\title{
Correction to: A new inherent reliability modeling and analysis method based on imprecise Dirichlet model for machine tool spindle
}

\author{
Zheng Liu $^{1}$ D $\cdot$ Xin Liu ${ }^{1} \cdot$ Hong-Zhong Huang ${ }^{2} \cdot$ Pingyu Zhu $^{1} \cdot$ Zhongwei Liang $^{1}$
}

(c) Springer Science+Business Media, LLC, part of Springer Nature 2019

\section{Correction to: Annals of Operations Research https://doi.org/10.1007/s10479-019-03333-9}

This erratum is published because vendor overlooked corrections related to equation 4 during proofing.

The original article has been thus corrected with the corrected references and thus updated.

The original article can be found online at https://doi.org/10.1007/s10479-019-03333-9.

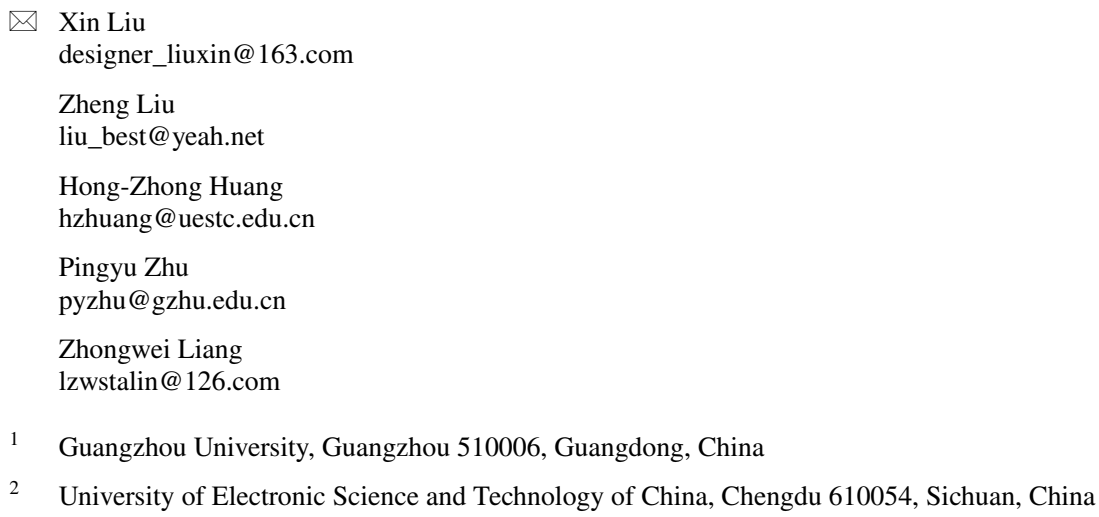

2 University of Electronic Science and Technology of China, Chengdu 610054, Sichuan, China 